УДК 577.2

DOI: $10.33184 /$ spbgb-2021-09-21.7

\title{
Роль генов антиоксидантной системы в формировании пред- расположенности к развитию цереброваскулярных заболева- ний: анализ ассоциаций однонуклеотидных полиморфизмов и метилирования ДНК
}

\author{
() О.Ю. Бушуева ${ }^{1 *}$, Е.М. Барышева ${ }^{1}$, А.В. Марков ${ }^{2}$, Ю.А. Королёва ${ }^{2}$, Е.О. Чуркин ${ }^{2}$, \\ М.С. Назаренко ${ }^{2}$, А.В. Полоников ${ }^{1}$, В.П. Иванов ${ }^{1}$ \\ ${ }^{1}$ Курский государственный медицинский университет \\ Россия, 305004, г. Курск, улица К. Маркса, 3. \\ ${ }^{2}$ Научно-исследовательский институт медицинской генетики, Томский националь- \\ ный исследовательский медицинский центр Российской академии наук \\ Россия, 634050, г. Томск, Набережная реки Ушайки, 10
}

\section{*Email: olga.bushueva@inbox.ru}

У 378 больных мозговым инсультом и 474 здоровых индивидуумов проведена оценка ассоциаций 16-и полиморфных вариантов генов антиоксидантной системы с риском развития заболевания. Установлена связь rs1128446 TXNRD1 (OR=1,93;95\% $\mathrm{Cl}=1,51$ 2,47); rs7493 PON2 (OR=1,80;95\%Cl=1,46-2,22); rs2266782 FMO3 (OR=1,24;95\%Cl=1,02$1,50)$ с повышенным риском развития МИ. Анализ метилирования антиоксидантных генов TXNRD1, GCLM, GSTP1 выявил у больных МИ снижение метилирования GSTP1 (среднего по исследованному региону показателя: 2,7 [2,3; 3,9]\%) по сравнению с контрольной группой $\left(4,4[3,6 ; 7,1] \% ; P=9,43 \times 10^{-6}\right)$. Также у больных МИ отмечалось снижение метилирования гена GCLM (среднего по исследованному региону показателя: $5,8[4,1 ; 7,1] \%)$ по сравнению с контрольной группой $(7,9[5,3 ; 10,3] \% ; \mathrm{P}=0,004)$.

Ключевые слова: мозговой инсульт, окислительный стресс, однонуклеотидный полиморфизм, метилирование ДНК.

Инсульт занимает третье место в структуре смертности во всем мире и является ведущим фрактором снижения когнитивных функций и деменции [1]. Данные исследований, накопленные за последние десятилетия, убедительно доказывают, что окислительный стресс, связанный с избытком активных форм кислорода (АФК), является основным механизмом повреждения головного мозга при мозговом инсульте (МИ) [2]. Окислительный стресс играет важнейшую роль в патогенезе МИ из-за высокой чувствительности мозга к АФК-индуцированным повреждениям. Мозг является чувствительной мишенью по многим причинам, в том числе ввиду высокой концентрации подверженных перекисному окислению липидов, высокого уровня потребления кислорода (20\% от всего организма), высокого уровня железа, которое может действовать как прооксидант при патологических состояниях [3]. Клинические исследования показали повышенный сывороточный уровень маркеров окислительного стресса даже спустя несколько месяцев после МИ, в основном, за счет изменения в сыворотке крови уровня антиоксидантов, вследствие чего существенно возрастает риск новых эпизодов ишемии [4]. Таким образом, окислительный стресс вызывает не только прямое и необратимое окислительное повреждение макромолекул, но также нарушает ключевые процессы редокс-зависимой сигнализации в артериальной стенке, и его влияние на церебральные сосуды в конечном итоге влияет на мозговое кровообращение. 
Целью настоящей работы стал молекулярный и эпигенетический анализ вовлеченности генов антиоксидантной системы в формирование предрасположенности к развитию мозгового инсульта.

Материалом для исследования послужила выборка неродственных, русских индивидов, проживающих в Курской области, общей численностью 852 человека. В исследование вошли 378 пациентов с МИ (217 мужчин, 161 женщина), которые находились на стационарном лечении в Региональном сосудистом центре Курской областной клинической больницы и в неврологическом отделении Курской Городской клинической больницы скорой медицинской помощи в период 2011-2017 гг [5-7]. Группу сравнения составили 474 практически здоровых добровольцев (263 мужчины, 211 женщин) без хронических заболеваний в анамнезе и имеющих нормальный уровень артериального давления. Исследуемые группы (больных МИ и контроля) были сопоставимы по полу $(\mathrm{P}>0,05)$. Средний возраст больных МИ составил 60 лет; средний возраст индивидуумов контрольной группы составил 59 лет (Р>0,05). Диагноз мозгового инсульта устанавливался в острейшей и острой фразах заболевания на основании результатов неврологического обследования и компьютерной томографии и/или магнитнорезонансной томографии головного мозга. Пациенты с печеночной и почечной недостаточностью, эндокринными, аутоиммунными, онкологическими и другими заболеваниями, которые могли вызвать острое нарушение мозгового кровообращения, были исключены из исследования. Из исследования также были исключены пациенты с вторичным внутримозговым кровоизлиянием, пациенты с гемодинамическим, гемореологическим и диссекционным типом инсульта, а также пациенты с черепно-мозговой травмой. Все пациенты с МИ имели в анамнезе артериальную гипертензию и получали гипотензивную терапию. Исследование было утверждено Региональным этическим комитетом Курского государственного медицинского университета. Все участники дали письменное информированное согласие на включение в исследование. Геномную ДНК выделяли стандартным методом френольно-хлороформной экстракции. Генотипирование однонуклеотидных полиморфизмов rs2070424 SOD1, rs4880 SOD2, rs769214 CAT, rs713041 GPX4, rs1128446 TXNRD1, rs17522918 PRDX1, rs41303970 GCLM, rs17883901 GCLC, rs854560 и rs662 PON1, rs7493 PON2, rs1695 GSTP1, rs2266782 FMO3, rs1800566 NQO1 проводили методом ПЦР в режиме «реального времени» путем дискриминации аллелей с помощью TaqMan зондов на амплификаторе CFX96, Bio-Rad (США); генотипирование делеционных полиморфизмов +/0 GSTM1, +/0 GSTT1 проводили методом мультиплексной ПЦР. Для анализа ассоциаций генотипов с МИ пользовали лог-аддитивную регрессионную модель с поправками на пол и возраст, рассчитанную в программе SNPStats. Значение P $\leq 0.05$ принималось как статистически значимое.

Статус метилирования был оценен на 113 образцах ДНК, выделенной из лейкоцитов периферической крови 31 больного МИ и 82 здоровых индивидов. Бисульфитную модификацию ДНК проводили с использованием коммерческого набора EZ DNA Methylation Kit (Zymo Research, США). Для оценки статуса метилирования были отобраны гены TXNRD1 (3 сайта), GSTP1 (2 сайта), GCLM (4 сайта). Степень метилирования оценивали методом пиросеквенирования на приборе PyroMark Q24 (Qiagen). Для сравнения уровня метилирования CpG-сайтов использовали U-критерий Манна-Уитни в программе SPSS Statistics v23.

С развитием МИ ассоциировались 3 SNP: rs1128446 TXNRD1 (OR=1,93;95\% Cl=1,512,47); rs7493 PON2 (OR=1,80;95\%Cl=1,46-2,22); rs2266782 FMO3 (OR=1,24;95\%Cl=1,021,50) (Таблица 1). 
Таблица 1. Результаты анализа ассоциаций исследованных SNP с развитием МИ.

\begin{tabular}{|c|c|c|c|}
\hline \multirow[t]{2}{*}{ Ген } & \multirow[t]{2}{*}{ rs } & \multicolumn{2}{|c|}{$\begin{array}{l}\text { Результаты анализа ассоциаций геноти- } \\
\text { пов (аддитивная модель) }\end{array}$} \\
\hline & & corOR $(95 \% \mathrm{Cl})^{\star}$ & cor $P^{* *}$ \\
\hline SOD1 & rs2070424 & $1.01(0.70-1.45)$ & 0,97 \\
\hline SOD2 & rs4880 & $1.04(0.86-1.27)$ & 0,67 \\
\hline$C A T$ & rs769214 & $0.87(0.71-1.07)$ & 0,18 \\
\hline GPX4 & rs713041 & $0.99(0.81-1.20)$ & 0,9 \\
\hline TXNRD1 & rs1128446 & $1.89(1.48-2.43)$ & $<0.0001$ \\
\hline PRDX1 & rs17522918 & $0.87(0.61-1.25)$ & 0,45 \\
\hline GCLM & rs41303970 & $1.19(0.95-1.49)$ & 0,13 \\
\hline GCLC & rs17883901 & $1.10(0.79-1.54)$ & 0,58 \\
\hline PON1 & rs854560 & $0.85(0.69-1.05)$ & 0,12 \\
\hline PON1 & rs662 & $1.20(0.96-1.50)$ & 0,11 \\
\hline PON2 & rs7493 & $1.79(1.45-2.21)$ & $<0.0001$ \\
\hline GSTM1 & $+/ 0(-)$ & $1.07(0.81-1.42)$ & 0,64 \\
\hline GSTT1 & $+/ 0(-)$ & $1.20(0.87-1.66)$ & 0,26 \\
\hline GSTP1 & rs1695 & $1.09(0.89-1.34)$ & 0,41 \\
\hline NQO1 & rs2266782 & $0.97(0.77-1.23)$ & 0,81 \\
\hline FMO3 & rs1800566 & $1.24(1.02-1.51)$ & 0,027 \\
\hline \multicolumn{4}{|c|}{$\begin{array}{l}\text { * - отношение шансов и 95\%-доверительный интервал с коррекцией на пол } \\
\text { и возраст; }\end{array}$} \\
\hline
\end{tabular}

У пациентов с МИ наблюдалось снижение метилирования гена GSTP1 (среднего по исследованному региону показателя: 2,7 [2,3; 3,9]\%) по сравнению с контрольной группой $\left(4,4[3,6 ; 7,1] \% ; P=9,43 \times 10^{-6}\right)$. Также у больных МИ отмечалось снижение метилирования гена GCLM (среднего по исследованному региону показателя: $5,8[4,1 ; 7,1] \%$ ) по сравнению с контрольной группой $(7,9[5,3 ; 10,3] \% ; P=0,004)$. Сравнительный анализ уровня метилирования TXNRD1 различий между больными МИ и здоровыми индивидуумами не выявил. 
Таким образом, гены антиоксидантной системы играют важную роль в предрасположенности к развитию цереброваскулярных заболеваний, как посредством ассоциаций однонуклеотидных полиморфизмов, так и посредством эпигенетических модификаций, связанных с изменением метилирования ДНК.

\section{Литература}

1. Mendis S., Davis S., Norrving B. Organizational update: the world health organization global status report on noncommunicable diseases 2014; one more landmark step in the combat against stroke and vascular disease //Stroke. 2015. V. 46. №. 5. P. e121-e122.

2. Yang Q. et al. Potential neuroprotective treatment of stroke: targeting excitotoxicity, oxidative stress, and inflammation //Frontiers in Neuroscience. 2019. V. 13. P. 1036.

3. Saeed S. A. et al. Some new prospects in the understanding of the molecular basis of the pathogenesis of stroke //Experimental brain research. 2007. V. 182. №. 1. P. 1.

4. Alexandrova M. L., Bochev P. G. Oxidative stress in stroke //Oxidative Stress and Neurodegenerative Disorders. 2007. V. 1. P. 313-368.

5. Bushueva O. Y., Stetskaya T. A., Korogodina T. V., Ivanov V. P., Polonikov A. V. The combined effect of E298D polymorphism of the endothelial nitric oxide synthase gene and smoking on the risk of cerebral stroke //Genetika. 2015. V. 51. №. 2. P. 256-262.

6. Bushueva O.Y., Stetskaya T.A., Korogodina T.V., Ivanov V.P., Polonikov A.V. Investigation of the association between the Hindlll polymorphism of the LPL gene and the Taq1b polymorphism of the CETP gene with the risk of atherothrombotic stroke in the dwellers of Central Russia //Therapeutic archive. 2015. V. 87. №. 8. P. 86-91.

7. Polonikov A., Vialykh E., Vasil'eva O., Bulgakova I., Bushueva O., Illig T., Solodilova M. Genetic variation in glutathione S-transferase genes and risk of nonfatal cerebral stroke in patients suffering from essential hypertension //Journal of Molecular Neuroscience. 2012. V. 47. №. 3. P. 511-513.

\section{The role of antioxidant-related genes in predisposition to the development of cerebrovascular diseases: analysis of associations of single nucleotide polymorphisms and DNA methylation}

O.Yu. Bushueva ${ }^{1 *}$, E.M. Barysheva ${ }^{1}$, A.V. Markov², Yu.A. Koroleva², E.O. Churkin², M.S. Nazarenko ${ }^{2}$, A.V. Polonikov ${ }^{1}$, V.P. Ivanov ${ }^{1}$

${ }^{1}$ Kursk State Medical University

3 K. Marx Street, 3305041 Kursk, Russia.

${ }^{2}$ Research Institute of Medical Genetics, Tomsk National Research Medical Center of the Russian Academy of Sciences

10 Nab. r. Ushaiki, 634050 Tomsk, Russia.

*Email: olga.bushueva@inbox.ru

In 378 patients with cerebral stroke (CS) and 474 healthy individuals, the analysis of associations of 16 SNP of the antioxidant-related genes with the risk of CS were assessed. 
SNP rs1128446 TXNRD1 (OR=1.93; 95\%Cl=1.51-2.47); rs7493 PON2 (OR=1.80; $95 \% \mathrm{Cl}=1.46-2.22)$; rs2266782 FMO3 (OR=1.24; $95 \% \mathrm{Cl}=1.02-1.50)$ were associated with an increased risk of CS. Analysis of methylation of antioxidant-related genes TXNRD1, GCLM, GSTP1 revealed a decrease in GSTP1 methylation in patients with CS (average for the studied region: $2.7[2.3 ; 3.9] \%)$ compared with the control group $\left(4.4[3.6 ; 7.1] \% ; P=9.43 \times 10^{-}\right.$ $\left.{ }^{6}\right)$. In patients with CS we also observed a decrease in methylation of the GCLM gene (average for the studied region: $5.8[4.1 ; 7.1] \%)$ compared with the control group (7.9 [5.3; 10.3]\%; $P=0.004)$.

Keywords: cerebral stroke, oxidative stress, single nucleotide polymorphism, DNA methylation. 